measure of gas mixing, Lung Clearance Index (LCI), derived from multiple breath washouts using sulphur hexafluoride as tracer gas and a modified Innocor gas analyser, to detect early airway changes in smokers with normal spirometry.

Methods Current cigarette smokers with a smoking history of over 10 pack years and no known cardiac or respiratory disease were recruited from smoking cessation clinics. Spirometry was performed to ERS standards before and after salbutamol. Participants with post-bronchodilator $\mathrm{FEV}_{1}<80 \%$ predicted, $\mathrm{FEV}_{1} / \mathrm{FVC}<0.7$, or a significant bronchodilator response were excluded from analysis. St George's Respiratory Questionnaire (SGRQ) was completed. LCI reported is the mean of at least two technically acceptable repeat measurements.

Results 17 participants remained after exclusions, mean age 44 years (range 31-57) and mean smoking history of 25 pack years (range 11-60). Mean (SD) post-bronchodilator $\mathrm{FEV}_{1}$ and $\mathrm{FEF}_{25-75}$ was 101 (12) and 80 (23)\% predicted respectively. Only one participant had $\mathrm{FEF}_{25-75}<60 \%$. There was a moderate negative correlation between smoking history and $\mathrm{FEF}_{25-75}(\mathrm{r}=-0.51, \mathrm{p}=0.037)$ but not between smoking history and $\mathrm{FEV}_{1}$. Mean (SD) LCI was 7.7 (0.98) with mean (SD) intra-visit coefficient of variation of 3.7 (2.5)\%. Eight participants had LCI $>7.5$ (95\% CI for LCI in normal subjects 5.9-7.5), suggesting impaired lung gas mixing. There was a negative correlation between LCI and $\mathrm{FEV}_{1}(\mathrm{r}=-0.55, \mathrm{p}=0.02)$ and between LCI and $\mathrm{FEF}_{25-75}(\mathrm{r}=-0.66, \mathrm{p}=0.004)$ but no significant correlation between LCI and smoking history or total SGRQ score. Mean (SD) total SGRQ score was 10.9 (7.5), 12 participants scoring over 7 (95\% CI for total SGRQ score in normal subjects 5-7). Total SGRQ did not correlate with smoking history, LCI, $\mathrm{FEV}_{1}$ or $\mathrm{FEF}_{25-75}$.

Conclusions These data support the hypothesis that LCI is a sensitive marker of early airway changes in smokers with normal $\mathrm{FEV}_{1}$ and $\mathrm{FEF}_{25-75}$. The effects of smoking cessation on this measure are currently being investigated.

\section{P130 LIMITS OF AGREEMENT FOR PEAK EXPIRATORY FLOW MEASURED BY MINI-WRIGHT'S METER AND A PNEUMOTACHOGRAPH}

doi:10.1136/thx.2010.150987.31

S J Oliver, E Ingram, D Fynn, D S Urquhart. Royal Hospital for Sick Children, Edinburgh, UK

Background Differences in peak expiratory flow (PEF) in children have been shown using a short exhalation PEF compared with a forced vital capacity (FVC) manoeuvre, when measured by turbine spirometry. Furthermore, PEF measures using a traditional Wright's scale PEF metre have been compared with those measured by FVC using a pneumotachograph in adults. The traditional Wright's scale may give rise to misleading results in children, and as such universal adoption of the EU scale has been advocated in the UK. To our knowledge, no study has compared PEF measured using a miniWright's EU scale PEF metre and PEF measured by FVC manoeuvres using a pneumotachograph in children.

Methods A retrospective review of children attending asthma clinic at a tertiary paediatric asthma clinic were carried out. Children underwent spirometry (Jaeger Masterscreen PFT Pro) using a pneumotachograph in accordance with ATS/ERS guidelines. In addition, peak expiratory flow (PEF) using a mini-Wright's PEF metre (Clement-Clarke International) was performed by each subject. Bland and Altman statistics were used to assess the limits of agreement for PEF measured by the two different techniques.

Results 161 children (90 male) aged 4-17 years with mean (sd) age of 10.1 (3.2) years were analysed. PEF measures varied from 87 to $613 \mathrm{l} / \mathrm{min}$ on spirometry, and from 100 to $570 \mathrm{l} / \mathrm{min}$ with the PEF metre. The mean (sd) difference between PEF measures by spiro- metry and PEF metre was 1.1 (23.5) 1/min. A Bland-Altman plot showing mean $(+/-2 S D)$ difference is shown (Abstract P130 Figure 1).

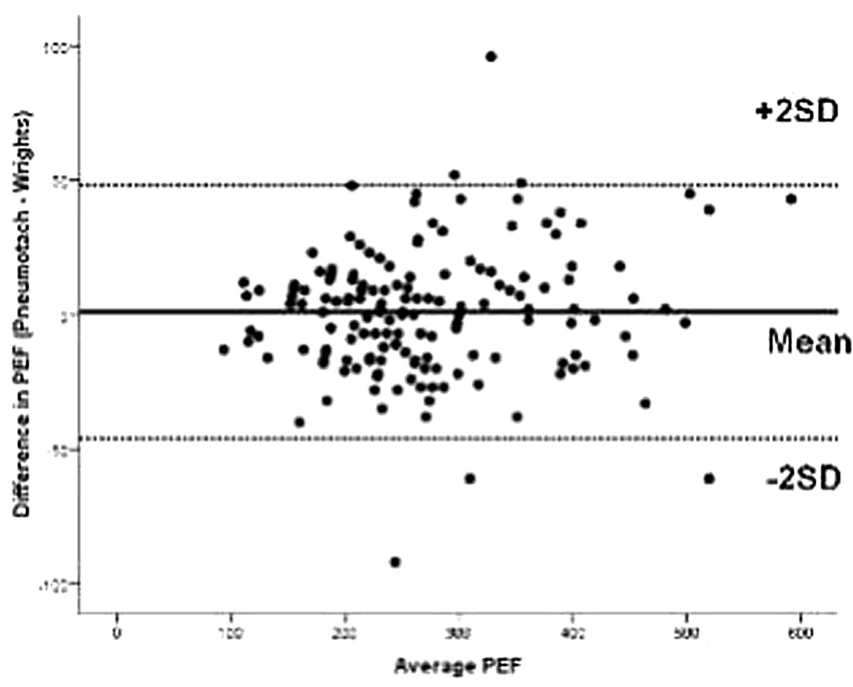

\section{Abstract P130 Figure 1}

Discussion Whilst close agreement for a childhood asthma population was demonstrated for two measures of PEF, individual differences could be quite marked with $100 \mathrm{l} / \mathrm{min}$ differences in PEF measurement being seen in either direction. One should be aware of potential differences in PEF measures when choosing testing equipment. Consideration should be given to dual measures of PEF in the setting of paediatric asthma (and not simply relying on a mini-Wright's PEF alone).

\section{P131 FITNESS TO FLY ASSESSMENT IN PATIENTS WITH NEUROMUSCULAR DISEASE}

doi:10.1136/thx.2010.150987.32

J Humphreys, S Agarwal, I Cliff, S Mathew, N Mustfa. University Hospital of North Staffordshire NHS Trust, Stoke On Trent, UK

Introduction Patients with neuromuscular disorders (NMD) can develop ventilatory impairment due to respiratory muscle weakness but despite disability, many travel by air. The British Thoracic Society (BTS) recommends hypoxic challenge test (HCT) in those who have baseline oxygen saturation ( $\mathrm{SpO} 2$ ) at sea level between $92-95 \%{ }^{1}$ However, this recommendation is based on very limited evidence.

Objectives To determine if baseline pulse oximetry at sea level provides a safe guide to predict hypoxia during flying and preclude a HCT in NMD patients.

Methods HCT performed on 12 NMD patients (11 Motor Neuron Disease and 1 Duchene's Muscular Dystrophy) attending ventilation clinic were retrospectively reviewed. HCT was performed to assess their fitness to fly irrespective of their baseline $\mathrm{SpO}_{2}$. A fall in $\mathrm{PaO}_{2}<6.6 \mathrm{kPa}$ was considered positive, $\mathrm{PaO}_{2}$ between 6.6 and $7.4 \mathrm{kPa}$ was considered borderline and $>7.4 \mathrm{kPa}$ was considered negative. ${ }^{1}$ Spirometry and sniff nasal inspiratory pressure (SNIP) were also recorded.

Results There were nine male and three female patients, age range 27-72 years (median 63 years). Four patients were positive for HCI and two had borderline results. Only two patients among this group met the criteria for HCT as per BTS recommendation. Six patients were negative for HCT and only one met the criteria for HCT. There was no difference in median $\mathrm{FEV}_{1}(1.85$ vs $2.04 \mathrm{~L} / \mathrm{s})$ and median FVC 